\title{
Monitoring the Physiological State in the Dark Fermentation of Maize/Grass Silage Using Flow Cytometry and Electrooptic Polarizability Measurements
}

\author{
Carlos E. Gómez-Camacho ${ }^{1}$ (1) $\cdot$ Klaus Pellicer Alborch ${ }^{2} \cdot$ Anika Bockisch $^{2} \cdot$ Peter Neubauer $^{2} \cdot$ Stefan Junne $^{2}$. \\ Bernardo Ruggeri ${ }^{1}$
}

Received: 25 February 2020 / Accepted: 18 August 2020 / Published online: 31 August 2020

(C) The Author(s) 2020

\begin{abstract}
Dark fermentation (DF), a key biohydrogen-producing process, is generally operated as a black-box, by monitoring different operative macroscopic process parameters without evaluating or tracking the physiology of the biotic phase. The biotic phase in DF is constituted by a large variety of microorganisms, mainly fermentative bacteria. The present study uses two (electro)optical techniques, flow cytometry (FC) and frequency-dependent polarizability anisotropy (FDPA) measurements, to gain insights into the physiology of open mixed consortia throughout the DF process. The mixed consortia for DF were obtained from a methanogenic sludge, selecting spore-forming bacteria by means of an acid treatment. Then, DF systems with and without $\mathrm{pH}$ control were studied, using as substrate a mixture of maize and grass silage $(9: 1 \mathrm{w} / \mathrm{w})$. Over the course of fermentation, the butyric pathway was dominant in both systems, and relevant titers of acetate, formate, and ethanol were detected; while hydrogen yields amounted to $20.80 \pm 0.05$ and $17.08 \pm 0.05 \mathrm{NmL} / \mathrm{gVS}$ under $\mathrm{pH}$-regulated and non-regulated conditions, respectively. The cytometric pattern analysis of the culture together with microscopic observations made it possible, over the course of fermentation, to identify and track the predominant morphologies in play (i.e., free spore, rod-shaped, and endospore, which are typical of Clostridium spp.). Furthermore, the use of the fluorescent dye $\mathrm{DiBAC}_{4}(3)$ in $\mathrm{FC}$ and FDPA measurements provided similar information regarding the physiological state (PS) of the mixed consortia during the different phases of the culture.
\end{abstract}

Keywords Dark fermentation · Biohydrogen · Physiological state $\cdot$ Flow cytometry · Frequency-dependent polarizability anisotropy

\section{Introduction}

The shift from oil-based economies to circular bioeconomic models is a growing concern of the biotechnological industry. In particular, the industrially feasible exploitation of different biomass resources and the vast microbial diversity is an

Electronic supplementary material The online version of this article (https://doi.org/10.1007/s12155-020-10184-x) contains supplementary material, which is available to authorized users.

Carlos E. Gómez-Camacho

carlos.gomezcamacho@polito.it

1 DISAT, Department of Applied Science and Technology, Politecnico di Torino, C/so Duca degli Abruzzi 24, 10129 Torino, Italy

2 Chair of Bioprocess Engineering, Institute of Biotechnology, Technische Universität Berlin, Ackerstrasse 76 ACK 24, 13355 Berlin, Germany important pillar for the production of bioenergy and biochemicals. Europe accounts for 224 biorefineries [1] that use various feedstock, such as bio-waste, lignocellulosic material, waste fats and oils, and sugar- and starch-rich residues, either for bioenergy or bio-based chemical production.

Dark fermentation (DF) and anaerobic digestion (AD) are consolidated anaerobic fermentative processes that are used for bioenergy $\left(\mathrm{H}_{2}\right.$ and $\left.\mathrm{CH}_{4}\right)$ and the production of biochemicals from organic waste or to stabilize activated sludges of wastewater treatments. Besides DF, biohydrogen can also be produced using photofermentation or other photobiological processes [2].

The DF and AD exploit open mixed cultures, composed of microorganisms belonging to the Archaea and Bacteria domains, where different biochemical cycles take place. The $\mathrm{AD}$ can be described as a concatenated succession of the following different phases: hydrolysis, acidogenesis, acetogenesis, and methanogenesis, while DF can be seen as a truncated version where methanogenesis does not take place. 
Fermentative bacteria are the main responsible organisms for hydrolysis and the two fermentative conversion stages (acidogenesis and acetogenesis), while methanogens are the terminal players in the trophic chain [3], converting the intermediates to the final products, $\mathrm{CH}_{4}$ and $\mathrm{CO}_{2}$.

The composition of the mixed cultures used in $\mathrm{DF}$ and $\mathrm{AD}$ has different proportions of hydrolytic fermentative bacteria that first hydrolyze (a) large macromolecules, such as polysaccharides, into small chain carbohydrates, (b) proteins into amino acids, and (c) lipids to glycerol, long-chain and shortchain carboxylic acids. In the first fermentation phase (acidogenesis), hydrolysis products feed different bacterial species, which in turn yield liquid-phase metabolites of interest, such as lactate, butyrate, propionate, acetate, ethanol, and gas-phase $\mathrm{H}_{2}$ and $\mathrm{CO}_{2}$. Thereafter, the second fermentation (acetogenesis) converts the primary fermented products into acetic acid, $\mathrm{H}_{2}$ and $\mathrm{CO}_{2}$, which are finally used in methanogenesis by hydrogenotrophic methanogens (which consume $\mathrm{CO}_{2}$ and $\mathrm{H}_{2}$ ) and acetoclastic methanogens (which consume acetic acid) and other substances (methylated compounds), to a lesser extent [3].

The DF can be conducted at different scales, using different types of bioreactors, such as continuously stirred tank reactors (CSTR), up-flow anaerobic sludge bed (UASB) reactors, anaerobic filter (AF) reactors, and fixed-bed reactors (FBR) [4]; each configuration presents particular features and dynamics, biohydrogen yields, and dominant bacterial species [5]. The $\mathrm{DF}$ can also be exploited in cascade reactor arrangements, for example coupling DF to AD in two-stage AD (TSAD) [6]. The TSAD optimizes process parameters to produce $\mathrm{H}_{2}$ and a mixed pool of carboxylic acids in the DF bioreactor (fermentative bacteria), while a second methanogenic bioreactor (fermentative bacteria and methanogens) is fed with the liquid output from the first reactor and targets $\mathrm{CH}_{4}$ production [7]. Alternatively, the liquid effluent of carboxylic acids and solvents from the DF process can be fed into different processes (see Fig. 1), thus increasing value addition and improving the sustainability of the process $[8,9]$. This can be achieved by additional energy production as it occurs in microbial fuel cells (MFCs) [10], algae and microalgae cultivations [11], and other multi-cascade reactor configurations [7], as well as in the synthesis of valuable chemicals [12].

Despite the advantages of the use of biohydrogen as clean fuel, there are certain limitations that have prevented production on a consolidated and cost-effective industrial scale. The photofermentation and photobiological processes require very specific cultivation conditions and have low efficiencies of light conversion and relatively low $\mathrm{H}_{2}$ yields $[2,13]$. Enzymatic systems suffer from sensitivity to $\mathrm{O}_{2}[8,14]$ and $\mathrm{H}_{2}$, which reduces the efficiency of these systems, although novel approaches are actively being researched to overcome this drawback [15]. Pure fermentative cultures (natural or engineered strains) require high sterilization costs that are currently unsustainable [9] and can lead to a negative net energy balance [8]. Open mixed fermentative cultures, such as those used in DF, are preferred due to their high production rates and their simplicity of operation [15]. However, they require elevated power input (mixing) to overcome thermodynamic inhibitions for high $\mathrm{H}_{2}$ productivity, and they are susceptible to metabolic shifts in long-term operated systems (e.g., solventogenesis, methanogenesis) [7].

Due to the inherent complexity and the intricate metabolic networks of mixed cultures in $\mathrm{DF}$ and $\mathrm{AD}$, these bioprocesses are often operated as "black-boxes" and are managed through heuristics, empirical knowledge, and macroscopic process parameters [7]. Different molecular techniques are available to decipher the black-box, for example by profiling the bacterial communities involved in these processes. These methods can serve to better understand the ecological relationships among the community members or to construct detailed metabolic pathways or genome-based models. However, they are currently expensive, require laborious and time-consuming sample preparations [16], and, therefore, are not suitable for realtime monitoring at industrial level for DF and AD. Despite the large uncertainties of molecular tools [17], bacterial and archaeal communities in DF and AD have shown similar taxonomic and functional compositions, either in laboratory or industrial scale [18]. A study of 20 different laboratory-scale DF bioreactors operated in four different countries shows that the Firmicutes phylum [19] plays a predominant role as key fermentative microorganisms (mainly belonging to the Clostridia and Bacilli classes); while other phyla, such as Proteobacteria, Bacteroidetes, and Chloroflexi, are found in a lesser proportion. An overview of the AD microbiome is presented in [20], which analyzes 134 samples from both laboratory- and full-scale biogas plants fed with a range of different substrates and located in seven different countries; the results indicate that bacterial phyla Firmicutes, Bacteroidetes, Coprothermobacter, Actinobacteria, Termotogae, and Chloroflexi are the most abundant and that the methanogenic community is almost exclusively represented by the phylum Euryarchaeota.

Besides profiling bacterial communities and functional relationships, new process analytical technologies (PATs) can serve to develop process monitoring and control strategies, following the principle of quality by design (QbD). This is of particular interest for the development of advanced monitoring systems in biorefineries [21]. The PATs have proven their potential in measuring critical process attributes, mainly for the pharmaceutical industry and biotechnological processes with monocultures [22], which often include monitoring the physiology of the biotic phase. Nevertheless, this potential can also be exploited in complex microbial cultures to provide insights into key features of these systems.

As early introduced by Malek [23], the physiological state (PS) of the biotic phase is influenced by the physicochemical 
Fig. 1 Possible process integration for dark fermentation (DF)

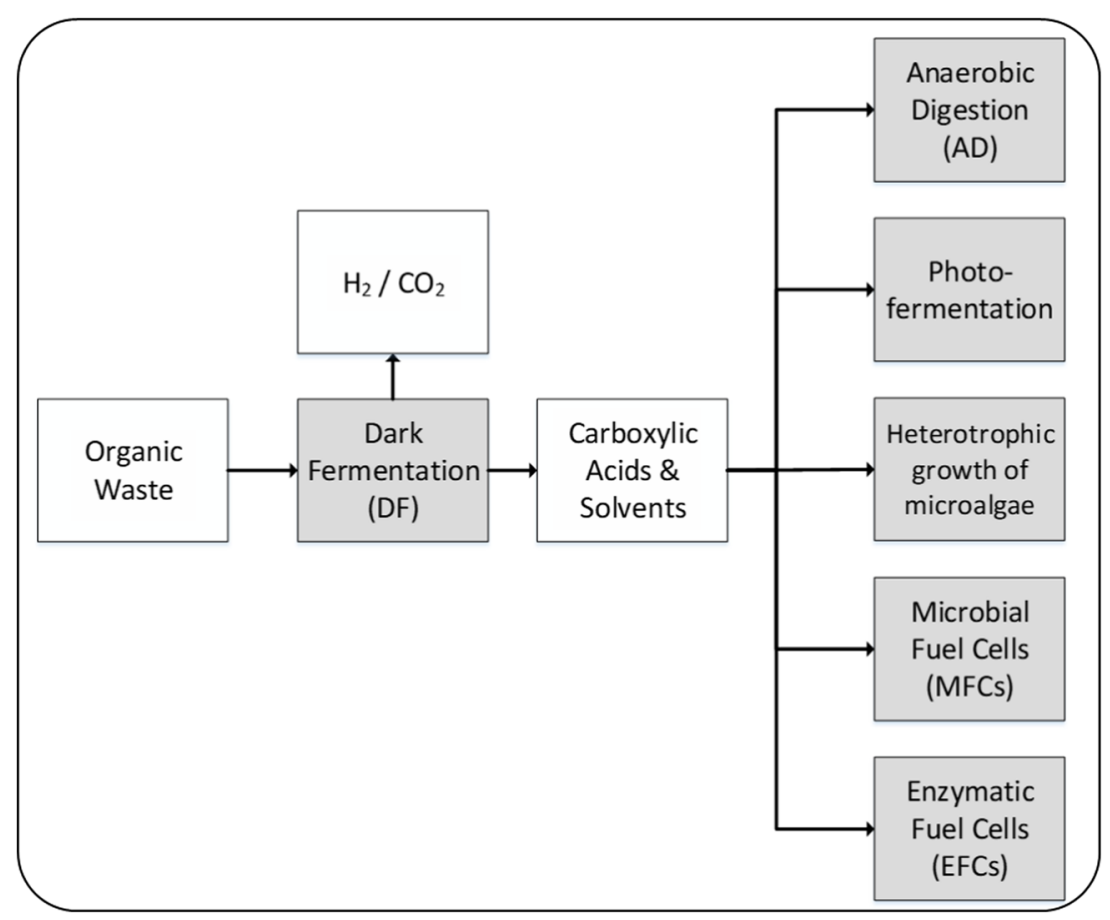

conditions of the environment and can either be a qualitative measure or be assessed through auxiliary parameters to monitor the process performance. The PS can thus be considered as a fitness indicator of culturing systems for their correct function and successful operation, which is a concept applicable to monocultures or mixed consortia. Hence, the compilation of key features of the biotic phase can provide better insights regarding the physiological state, such as morphology (shape and size of cells), the state of nucleic acids, the functionality of certain enzymes or redox cofactors, the status of transport mechanisms, and the membrane potential, among others [24].

Recent developments in (electro)optical techniques have allowed developing versatile PATs, which can be used for monocultures or microbial communities, even if microbial communities exhibit a higher level of complexity. One important platform, which is available for high throughput analysis of cells, is flow cytometry (FC). FC is a laser-based technique, which collects optical characteristics of cell suspensions, such as light scatter and fluorescence. Microbial morphological heterogeneities can be examined, in terms of relative cell size and granularity, by using the forward scatter (FSC) and side scatter (SSC) signals. Additionally, fluorescence detectors can further collect information of qualitative and quantitative nature, regarding the PS of several thousand cells per second, using specific dyes (bound to certain molecules and/or structures) or exploiting auto-fluorescent properties of different cell types [25]. The FC is widely used in medical and diagnostic applications [26] and has also been proposed as a tool to determine the heterogeneity of microbial monocultures due to physicochemical gradients appearing within culturing systems when grown in industrial-scale fermenters [27]. Recently, it has been used to characterize microbial community dynamics by analyzing the cytometric print (i.e., morphology-based clusters of virtual populations generated from the FSC/SSC data) [28]. However, only a few experimental data are available regarding the application of FC for bioenergy production. For instance, $\mathrm{FC}$ has been employed to monitor the culture dynamics in an AD system under substrate overload (i.e., increasing the organic loading rate) [29] to estimate the stability of the microbial community by analyzing segregated cell abundance in different clusters. The results showed that perturbations created abundance changes in three acidogenic subcommunities instead of variations in the microbiome phylogenetic composition. In addition, recent studies have also used the FC platform to evaluate morphological traits of Clostridium beijerinckii monocultures, in particular, monitoring different cell stages and the share of sporulating cells [30]. A practical application of PS monitoring of a thermophilic DF system has been reported in [31], using propidium iodide staining in FC measurements.

Another electrooptical technique to monitor the PS of microorganisms uses the relative changes in light absorption of cell suspensions under the application of an electric field at different frequencies, which has been termed frequencydependent polarizability anisotropy (FDPA). The application of an electric field induces a rotational moment on charged particles that can be described by means of polarizability tensors. Following the electrophysical model, certain bacterial cells can be considered axially symmetrical ellipsoids of 
revolution, which accumulate electric charges (i.e., membrane potential) at the interface between two media with different dielectric properties: the cytoplasm and suspension medium (segregated by the non-conductive layer of the lipid membrane). The mismatch of the electric properties at the cellmedium interface due to the Maxwell-Wagner polarization can be quantified using the changes in the absorption of orthogonally located light beams, $\alpha \|(w)$ and $\alpha \perp(w)$, and used to calculate the FDPA as $d \alpha(w)=\alpha \|(w)-\alpha \perp(w)$ [32]. Relative changes in this parameter can be considered an integral property reflecting the PS of microorganisms, as a result of the different levels of ion accumulation in the biotic phase. FDPA measurements have previously been used as an indicator of the PS of cell suspensions, although most of the cases pertain to monocultures. For instance, FDPA levels have been used to monitor the PS of aerobic Escherichia coli cultivations at different temperatures [33], to follow the acidogenicsolventogenic metabolic shift in Clostridium acetobutylicum [34] and to investigate the performance of Lactobacillus plantarum under different stress conditions, such as nonpH-regulated conditions, different substrate concentrations, nutrient limitations, and suboptimal cultivation temperature [35]. Recently, the applicability of FDPA to monitor the PS of mixed cultures has been tested; Habermann et al. [36] measured the FDPA of different AD systems using corn silage as feedstock and obtained decreasing FDPA values under acidification stress, suggesting the PS of the biotic phase in $\mathrm{AD}$ systems and sewage sludges can also be monitored through FDPA measurements.

In the present study, a simple method is used for the selection of an open mixed culture for the production of biohydrogen (hydrogen-producing bacteria, HPB) from a methanogenic AD sludge. Then, the HPB culture is used as inoculum of mesophilic DF tests, using as substrate a mixture of maize and grass silage, under $\mathrm{pH}$-regulated and non-regulated conditions. During the course of fermentation, a batch-tobatch monitoring is performed following key parameters, such as $\mathrm{pH}$ evolution, biohydrogen yields, carboxylic acids, and ethanol titers in the liquid phase; while insights into the PS of the biotic phase are gained through FC and FDPA measurements.

\section{Materials and Methods}

\section{Preparation of the HPB Inoculum}

The biohydrogen-producing inoculum was obtained following a selection procedure that aims to suppress methanogenic activity from an $\mathrm{AD}$ sludge. Although several efficient strategies can be applied to obtain hydrogen-producing bacteria (HPB) from AD sludges [37, 38], the combination of acid/aerobic stresses was chosen to promote sporulation of Firmicutes, in particular,
Clostridium spp., which are anaerobic microorganisms, capable of forming spores. A sludge from an on-going AD plant digesting agricultural wastes was treated at $\mathrm{pH}=3.0$, using a $10 \mathrm{M} \mathrm{HCl}$ solution, and placed under aerobic conditions for $24 \mathrm{~h}$ at $35^{\circ} \mathrm{C}$ in an incubation chamber (Multitron II-Infors HT, Bottmingen, Switzerland). The $\mathrm{pH}$ was then set to 6.0 , and the resulting broth (spore-enriched due to the acid treatment) was then pre-cultivated under anaerobic conditions for $12 \mathrm{~h}$ at $35^{\circ} \mathrm{C}$, using a $30 \mathrm{~g} / \mathrm{L}$ glucose media, prior to the inoculation of the $\mathrm{DF}$ systems to run the tests (the "Experimental Set-Up of the DF System" section).

\section{Preparation and Pre-Treatment of the Substrate}

The substrate for the DF tests was a mixture of agricultural products composed of maize and grass silage, mixed in a proportion of 9:1 $(w / w)$. The proximate analyses of these feedstocks are reported in Table 1. Fresh materials were grinded with a laboratory batch mill (IKA-A10 Werke, Staufen, Germany) to decrease the particle size and subsequently diluted with tap water (4:11 w/w) to facilitate mixing during the fermentation process. The substrate media was pre-treated with a $30 \%(w / w) \mathrm{NaOH}$ solution, until $\mathrm{pH}=12$ was reached and incubated at $35^{\circ} \mathrm{C}$ for $24 \mathrm{~h}$ in the aforementioned incubation chamber.

Table 1 Raw substrate proximate analyses

\begin{tabular}{|c|c|c|c|c|c|c|}
\hline \multirow[b]{3}{*}{ Dry matter (DM) } & \multicolumn{3}{|c|}{ Corn silage } & \multicolumn{3}{|c|}{ Grass silage } \\
\hline & \multicolumn{3}{|c|}{$\left(\mathrm{g} / \mathrm{kg}_{\mathrm{FM}}\right)$} & \multicolumn{3}{|c|}{$\left(\mathrm{g} / \mathrm{kg}_{\mathrm{FM}}\right)$} \\
\hline & 371.0 & \pm & 17.3 & 491 & \pm & 35.1 \\
\hline Organic matter $(\mathrm{OM})$ & 356.9 & \pm & 23.6 & 443.4 & \pm & 37.0 \\
\hline Moisture & 629.0 & \pm & 8.1 & 509 & \pm & 41.4 \\
\hline Total ash & 14.1 & \pm & 0.3 & 47.6 & \pm & 1.8 \\
\hline Crude protein $(\mathrm{CP})$ & 23.4 & \pm & 0.5 & 82 & \pm & 3.0 \\
\hline Crude fiber & 76.4 & \pm & 5.6 & 118.3 & \pm & 4.9 \\
\hline Carbohydrates & 123.9 & \pm & 10.9 & - & \pm & - \\
\hline Crude fats & 10.4 & \pm & 0.8 & 15.7 & \pm & 0.2 \\
\hline ELOS & 252.3 & \pm & 6.1 & 317.2 & \pm & 7.9 \\
\hline $\mathrm{ADF}$ & 89.4 & \pm & 4.6 & 143.9 & \pm & 5.0 \\
\hline NDF & 154.0 & \pm & 2.8 & 232.7 & \pm & 17.1 \\
\hline NFC & 169.2 & \pm & 12.0 & 112.9 & \pm & 8.7 \\
\hline Avail. CP & 46.7 & \pm & 3.5 & 66.3 & \pm & 2.5 \\
\hline Ammonia & 0.6 & \pm & 0.1 & 1.8 & \pm & 0.1 \\
\hline $\mathrm{NH}_{3}-\mathrm{N}$ of total $\mathrm{N}(\%)$ & 12.6 & \pm & 0.6 & 11.5 & \pm & 0.7 \\
\hline BGP $\left(\mathrm{m}^{3}\right.$ biogas $\left./ \mathrm{t}_{\mathrm{FM}}\right)$ & 234.8 & \pm & 7.9 & 286.1 & \pm & 7.8 \\
\hline $\operatorname{BMP}\left(\mathrm{m}^{3} \mathrm{CH}_{4} / \mathrm{t}_{\mathrm{FM}}\right)$ & 123.3 & \pm & 8.3 & 150.2 & \pm & 11.7 \\
\hline
\end{tabular}

FM, fresh matter; DM, dry matter; OM, organic matter; CP, crude protein; ELOS, enzymatic soluble organic matter; ADF, acid-detergent fiber; NDF, neutral-detergent fiber; NFC, non-fibrous carbohydrates; BGP, biogas potential; BMP, biomethane potential 


\section{Experimental Set-Up of the DF System}

The DF experimental tests were conducted in $1 \mathrm{~L}$ STR EloFerm bioreactors (EloSystems GbR, Berlin, Germany) with a working volume of $400 \mathrm{~mL}$. The empty vessels were sterilized $\left(121^{\circ} \mathrm{C}\right.$ for $\left.20 \mathrm{~min}\right)$, filled with the pre-treated substrate, and inoculated with the pre-cultivated HPB inoculum in a ratio of $10 \%(v / v)$. Bioreactors were operated at mesophilic conditions $\left(35^{\circ} \mathrm{C}\right)$ and under anaerobic conditions achieved by flushing $\mathrm{N}_{2}$ for $10 \mathrm{~min}$ into the fermentation broth at the beginning of the tests. The bioreactors were stirred magnetically, at a rate of $200 \mathrm{rpm}$. Two bioreactors were operated in parallel: in the first fermenter (A), a $\mathrm{pH}=6.0$ was fixed as set point and controlled with an integrated control loop of the EloFerm system using a 30\% $(w / w) \mathrm{NaOH}$ solution, while in the second bioreactor $(\mathrm{B})$, the $\mathrm{pH}$ remained uncontrolled throughout the course of fermentation.

\section{Analytical Measurements}

\section{Gas Analysis}

The produced gas of each bioreactor was first dried in a silicagel bed. The composition was measured online by means of a gas analyzer arrangement. It consisted of three in-series connected gas sensors (BlueSens, Herten, Germany): $\mathrm{BPC}-\mathrm{CO}_{2}$ and $\mathrm{BPC}-\mathrm{CH}_{4}$, based on infrared (IF) absorption for $\mathrm{CO}_{2}$ and $\mathrm{CH}_{4}$, respectively, and $\mathrm{BPC}-\mathrm{H}_{2}$, based on thermal conductivity difference to estimate the amount of $\mathrm{H}_{2}$. The total gas flow was measured using the water-displacement method: connecting the output of the gas analyzer arrangement to acidic water $(\mathrm{pH}=2.0)$, which displaces water-filled gas-meter flasks, ending up to collector bottles placed on analytical balances. The biohydrogen yield of each DF system is reported in normal milliliters per gram of volatile solid ( $\mathrm{NmL} / \mathrm{gVS}$ ), which are the standard units used in the field of biogas production that allow comparing systems at different conditions (e.g., pressure/temperature) for complex feedstocks (i.e., based on the organic matter or volatile solid content, see Table 1 for the proximate analysis).

\section{Quantification of Short-Chain Carboxylic Acids and Solvents}

Raw samples were first filtered with $125 \mu \mathrm{m}$ nylon filters (Carl Roth $\mathrm{GmbH}$, Karlsruhe, Germany) and then using syringe filter units (i.e., pore size $0.45 \mu \mathrm{m})$ and subsequently diluted $(1: 1 v / v)$ with ultra-deionized water provided by an Easypure II RF device (Barnstead, Iowa, USA). High-performance liquid chromatography (HPLC) was used to analyze the liquid phase, in particular shortchain carboxylic acids and solvents. The HPLC system (1200-series Agilent Technologies, Waldbronn, Germany), equipped with a refractive index detector (RID) and a $300 \times 7.7 \times 8 \mathrm{~mm}$ HyperRez $^{\mathrm{TM}}$ XP Carbohydrate $\mathrm{H}^{+}$column (Fisher Scientific,
Schwerte, Germany), was operated at $65{ }^{\circ} \mathrm{C}$ using $5 \mathrm{mM} \mathrm{H}_{2} \mathrm{SO}_{4}$ solution as eluent, at a flow rate of $0.6 \mathrm{~mL} / \mathrm{min}$ for a cycle time of $50 \mathrm{~min}$ [39]. A four-point calibration was performed for the detection of formate, acetate, propionate, butyrate, ethanol, propanol, and butanol in the operative range of the DF.

\section{Flow Cytometry Analysis}

For the FC analysis, samples were collected at the beginning of the fermentation in order to set the optimal detector sensitivities (by voltage adjustment) for each channel and with unstained cells (negative control). Samples collected from each bioreactor (A and $\mathrm{B}$ ) were vacuum filtered using $0.2 \mu \mathrm{m}$ paper filters, previously wetted with phosphatebuffered saline solution (PBS composition: $136.90 \mathrm{mM}$ $\mathrm{NaCl}, 2.70 \mathrm{mM} \mathrm{KCl}, 8.10 \mathrm{mM} \mathrm{Na} \mathrm{HPO}_{4} \cdot 2 \mathrm{H}_{2} \mathrm{O}$, and $1.80 \mathrm{mM} \mathrm{KH}_{2} \mathrm{PO}_{4}, \mathrm{pH}=7.2$ ). Five rinsing cycles of $1 \mathrm{~mL}$ PBS solution were applied to the solids retained in the filter paper to remove debris and impurities. The filter papers, containing the retained biotic phase, were immersed in $10 \mathrm{~mL}$ PBS after the washing steps $(5 \times 1 \mathrm{~mL}$ PBS $)$, briefly vortexed and diluted until a cell concentration of $1 \cdot 10^{6}$ cells $/ \mathrm{mL}$ prior to staining. The fluorochrome $\mathrm{BOX}$, also called $\mathrm{DiBAC}_{4}(3)$ or bis-(1,3-dibutylbarbituric acid) trimethine oxonol, was employed to stain the cells. Aliquots of $200 \mu \mathrm{L}$ were stained with BOX, at a final concentration of $0.5 \mu \mathrm{g} / \mathrm{mL}$ together with dissolved EDTA $(\sim 29.75 \mu \mathrm{g} / \mathrm{mL})$, at room temperature for 4 min to assess the relative amount of depolarized cells. Positive controls to assess the suitability of BOX-staining for the mixed consortia (HPB) were performed by applying a thermal treatment to the biological material of $80^{\circ} \mathrm{C}$ for $1 \mathrm{~h}$ using the BOX/EDTA mixture and the same staining conditions (4 min). Finally, the samples were analyzed by means of a MACSQuant Analyzer (Miltenyi Biotech, BergischGladbach, Germany), equipped with three lasers (violet $405 \mathrm{~nm}$, blue $488 \mathrm{~nm}$, and red $635 \mathrm{~nm}$ ), several filters and mirrors, two photomultiplier tubes for the detection of scattered light (FSC, SSC), and eight photomultiplier tubes for the detection of fluorescent signals. When bacteria samples present suitable characteristics to be hydrodynamically focused by FC, the FSC signal aims to discriminate cells based on the scattered light in the same axis as the incident light beam (i.e., often used an indicator of the cell length, although the more general interpretation considers FSC as a measure of cell size or volume), while SSC collects scattered light at an angle of $90^{\circ}$ to the incident beam, which provides information about cell complexity, granularity, and/or cell surface.

\section{Frequency-Dependent Polarizability Anisotropy Measurements}

Samples were first filtered with $125 \mu \mathrm{m}$ nylon filters (Carl Roth $\mathrm{GmbH}$, Karlsruhe, Germany) in order to remove large 
debris and inert particles. Subsequently, filtrate aliquots $(10 \mathrm{~mL})$ were centrifuged at $4{ }^{\circ} \mathrm{C}$ and $600 \mathrm{rpm}$ for $5 \mathrm{~min}$. The supernatant was diluted with ultra-deionized water (approx. 1:10 v/v) to adjust the initial electrical conductivity of the samples to an adequate range compatible with FDPA measurements $(<40 \mu \mathrm{S} / \mathrm{cm})$. FDPA measurements were conducted at line with samples extracted from bioreactor A and B at the following different time points: 1,20 , and $33 \mathrm{~h}$ of fermentation using an EloTrace device (EloSystems GbR, Berlin, Germany). The FDPA levels of each sample were acquired at different frequencies of the low and medium frequency spectrum ranges, namely 210, 400, 900, and $2100 \mathrm{kHz}$, based on the type of analyzed fermentation broth and previous exploratory tests. The mean values are presented together with the standard deviation of the triplicates measured for each sample. The FDPA values are displayed using arbitrary units of the equipment, scaled by a factor of 5 . $10^{-31} \mathrm{~F} \mathrm{~m}^{2}$ (i.e., farad square meters) [40], for easier representation and comparison with literature data.

\section{Statistical Analysis}

The statistical significance was evaluated using SigmaPlot 10.0; the Student's $t$ test was performed as pairwise comparisons (systems A and B) at different timepoints for the FDPA and FC tests. Additional details are provided in the Supplementary Material.

\section{Results and Discussion}

\section{DF Cultivation Performance}

The DF systems were set following the procedure described in the "Experimental Set-Up of the DF System" section; the bioreactors were operated with (A) and without (B) $\mathrm{pH}$ control. The acid-treatment applied to the $\mathrm{AD}$ sludge to obtain the HPB inoculum proved to be effective, since methanogenic activity was not detected during the tests. Throughout the DF experiments, no methanogen growth was appreciated in microscopic observations nor was methane production detected at the off-gas analyzer arrangement (see the "Gas Analysis" section). As a matter of fact, the continuous analysis of gaseous matrices using multiple gas sensors has been recently tested as a useful strategy for the course analysis of DF systems. Particularly, methane sensors can be useful to identify if populations (e.g., Archaea) and metabolic shifts occur in the DF systems [41].

Figure $2 \mathrm{a}$ shows the $\mathrm{pH}$ courses for both systems while the cumulative $\mathrm{H}_{2}$ yield is reported in Fig. 2b. During the tests, the $\mathrm{pH}$ value shows the following three different phases: an oscillating behavior around the initial $\mathrm{pH}$ value of the systems during the first $20 \mathrm{~h}$ of the fermentation;

ii) a regulated $\mathrm{pH}$ signal at a $\mathrm{pH}=6.0$ for the system (A) and a strong decrease for the non-regulated system (B) in the interval $20-33 \mathrm{~h}$; and

iii) a constant $\mathrm{pH}$ signal at 6.0 and 5.1 , for (A) and (B), respectively, until the arrest of the fermentation processes (33-40 h).

In the first $5 \mathrm{~h}$, the microorganisms seem to adapt to the new substrate and environmental conditions. These initial oscillations can be linked to the hydrolytic step during the first hours [42] and can be explained by considering two concomitant occurring phenomena: a slight $\mathrm{pH}$ decrease due to the production of moderate titers of volatile fatty acids (VFA) and a $\mathrm{pH}$ increase because of the dissolution and reaction of the $\mathrm{CO}_{2}$ produced by decarboxylation reactions and consequently a basification due to the formation of bicarbonate (coupled to a low production of $\mathrm{H}_{2}$ as shown in Fig. 2b). During this phase, a similar gas evolution in both systems was recorded. Hence, microbial activity was predominantly hydrolytic, i.e., oriented towards the production of enzymes and other biologically active molecules, necessary to attack the slowly degradable fraction [40]. The latter amounted to $\sim 21 \%$ of the organic matter for corn silage and to $\sim 27 \%$ for grass silage (Table 1), and this phase was accompanied by a slow $\mathrm{H}_{2}$ production rate and low carboxylic acid production. During the following hours ( $15 \mathrm{~h}$ ), the $\mathrm{pH}$ oscillatory behavior was still present. Nevertheless, the biohydrogen production rate increased for both systems. Then, an exponential growth phase of about 12 $13 \mathrm{~h}$ took place, which yielded different carboxylic acids titers in the liquid phase and gas production $\left(\mathrm{H}_{2}+\mathrm{CO}_{2}\right)$ with a decreasing $\mathrm{pH}$ trend in (B) and constant $\mathrm{pH}$ value for (A), at $\mathrm{pH}=6.0$ (due to the $\mathrm{pH}$ control). Finally, the cells entered the stationary phase (after $33 \mathrm{~h}$ ), and the evolution of gas ceased, while the $\mathrm{pH}$ values remained constant.

Cumulative hydrogen yields amounted to $20.80 \pm 0.05$ and $17.08 \pm 0.05 \mathrm{NmL} / \mathrm{gVS}$ for the system (A) and (B), respectively (see Fig. 2b). The gas production followed a similar trend for both systems. However, the mean $\mathrm{H}_{2}$ production rate was higher for the $\mathrm{pH}$-regulated system, while the concentrations of the gas phase were about $28.3 \pm 0.5$ and $26.0 \pm 0.8 \%$ $v / v$, with a correspondent $\mathrm{CO}_{2}$ fraction of 71.7 and $74.0 \% \mathrm{v} / \mathrm{v}$, for (A) and (B), respectively. As noted by [43], a pH control in the DF systems promotes higher $\mathrm{H}_{2}$ production using either suspended or immobilized DF microbial systems; in the present case, about $18 \%$ more $\mathrm{H}_{2}$ was obtained for the $\mathrm{pH}$ regulated system.

For simple sugar feedstocks and monoculture systems, the maximum biohydrogen yield can be calculated using stoichiometry; while for complex feedstocks and open mixed cultures, the yield strongly depends on the selected inoculum, the 
Fig. 2 Course of $\mathrm{pH}$ value (a) and hydrogen yields (b) during the DF tests
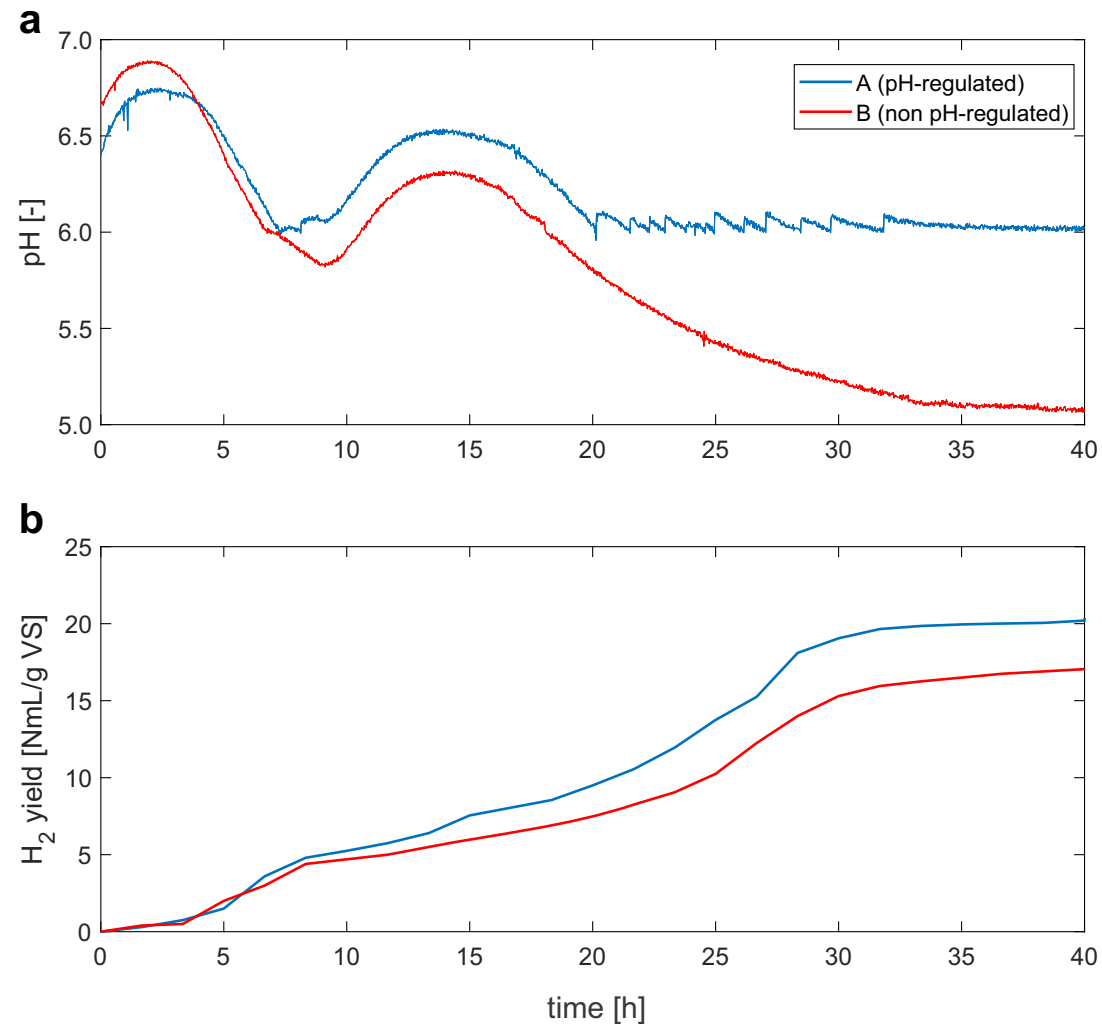

culturing conditions, and the feedstock pre-treatment. The obtained yields for system A and B are thus compared with some literature references for similar matrices, highlighting the source of the acidogenic inoculum (HPB), the pre-treatment of the feedstocks, the $\mathrm{pH}$ and culturing temperature, and the biohydrogen yields in each case (see Table 2). In these studies, the acidogenic inocula are selected from methanogenic sludges using different selective pressures (e.g., heat shock, substrate overload), the process conditions are mesophilic or thermophilic, and the feedstocks (grass and maize silages) are pre-treated using different strategies (mechanical, acid, basic, and enzymatic treatments). Besides, the biotic phase is not studied in detail, while the optimization of the process in certain of these studies is performed based on macroscopic process conditions, such as optimal $\mathrm{pH}$ and temperature, to target enhanced biohydrogen yields.

The $\mathrm{pH}$ value is a key parameter not only governing the microbial activity towards $\mathrm{H}_{2}$ productivity, but also influencing the production of other metabolites by activating different biological pathways [37, 43]. For instance, the analysis of supernatant samples (Fig. 3) revealed some differences between the system with (A) and without $\mathrm{pH}$ control (B). Despite the different $\mathrm{pH}$ conditions, the butyric acid fermentation was predominant for both systems with three-fold higher titers compared with the rest of detected carboxylic acids and ethanol. The $\mathrm{pH}$-controlled system produced a higher amount of acetic acid and ethanol towards the end of the fermentation (20-33 h), while the yield of these compounds in the non $\mathrm{pH}$-regulated system was rather modest. Moreover, for system (A), formic acid levels remained almost constant ( $\pm 2 \mathrm{mM}$ ), while for system (B), a slight formic acid consumption was observed in the exponential $\mathrm{H}_{2}$ production phase $(20 \mathrm{~h})$. Lastly, propionic acid remained almost unaltered for both systems; hence, nor production or consumption was observed in the systems. In fact, the measured titers of propionic acid remained $<2 \mathrm{mM}$, which is well below inhibition thresholds reported in the literature for similar DF systems [50].

In acid fermentations, particularly those where Firmicutes and specially Clostridium spp. take part, low $\mathrm{pH}$ levels are believed to induce the shift from acidogenesis to solventogenesis. The final $\mathrm{pH}$ for the regulated system (A) was 6.0 , while for the non-regulated systems was $\sim 5.1$, which are higher values compared with the solventogenic range of Clostridium spp. $\left(\mathrm{pH}_{\text {solventogenesis }}<4.5\right.$ [51]). This shift has been studied in pure and mixed cultures, and among other reasons, it represents a strategy to overcome $\mathrm{pH}$ stress by partial reutilization of a share of the produced acids [52].

\section{Flow Cytometry}

The FC allows the monitoring of the morphology of the biotic phase during the process. First, the morphology of the mixed consortia was analyzed using the bivariate 
FSC/SSC density plots complemented with the correspondent histograms. The information provided by the FSC/ SSC channels of FC served to differentiate among morphological traits of different subpopulations (i.e., relative cell length and granularity, see the "Flow Cytometry Analysis" section). As presented in Fig. 4a, the acid treatment of the AD sludge to select HPB resulted in a sporeenriched broth, which presents a cytometric print consisting mainly in one differentiable population, with unimodal histograms for the FSC and SSC channel (Fig. $4 b$ ). The pre-cultivation phase (pre-culture $=$ growth of the inoculum for the DF tests) allowed a fraction of these initial free-spore to germinate, into the characteristic rod-shaped morphology (i.e. which is typical for many acidogenic bacteria, such as Clostridium spp.) and endospore/forespore form (Fig. 4a and c). This was reflected in a bimodal distribution in the SSC channel and three populations in the FSC channel (Fig. 4b). The FSC/SSC print can be associated, crossing the information with optical microscopy observations (Fig. 4c), to (a) the non-germinated fraction of free spores, (b) rod-shaped vegetative (germinated) cells, and (c) endospores. This assessed morphology distribution after pre-cultivation coincides with the first measurement point of the DF ( $t=$ $1 \mathrm{~h})$ and is common for both systems. A similar cytometric print was found for the second measuring point $(t=$ $20 \mathrm{~h}$ ), although modest changes can be appreciated. A virtual clustering technique was applied to keep track of the changes in the cytometric prints, hypothesizing that they correspond to the observed morphologies as shown in Table 3. The trend of these sub-populations (virtual clusters) indicated that the relative fraction of free spores did not vary significantly, increasing by $4.8 \%$ for system (A) and about $6.1 \%$ for (B). Concomitant reductions in the share of rod-shape cells were observed, amounting to $4.8 \%$ for the system (A) and $7.74 \%$ for (B). Interestingly, the population of endospores remained almost unaltered for system (A), while an increase of $1.66 \%$ was reported for (B) (see Table 3). At the end of the DF tests $(t=33 \mathrm{~h})$, the cytometric print showed a significant shift from vegetative cells towards free-spores (i.e., sporulation) in both systems, which resulted in final amounts of free spores of more than half of all detected cells, which were used as a calculation base for FC analysis (Fig. 4d): 55.50 and $54.05 \%$ for (A) and for (B), respectively. This shift in the microbial population is consistent with the arrest of the biohydrogen production and probably reflects the response of the mixed consortia to starvation conditions.

Another set of tests was performed using the FC platform by staining samples with $\operatorname{DiBAC}_{4}(3)$ in order to track relative changes in the number of (partially) depolarized cells within the mixed HPB consortia. The 
Fig. 3 Carboxylic acids and ethanol titers measured during the DF tests

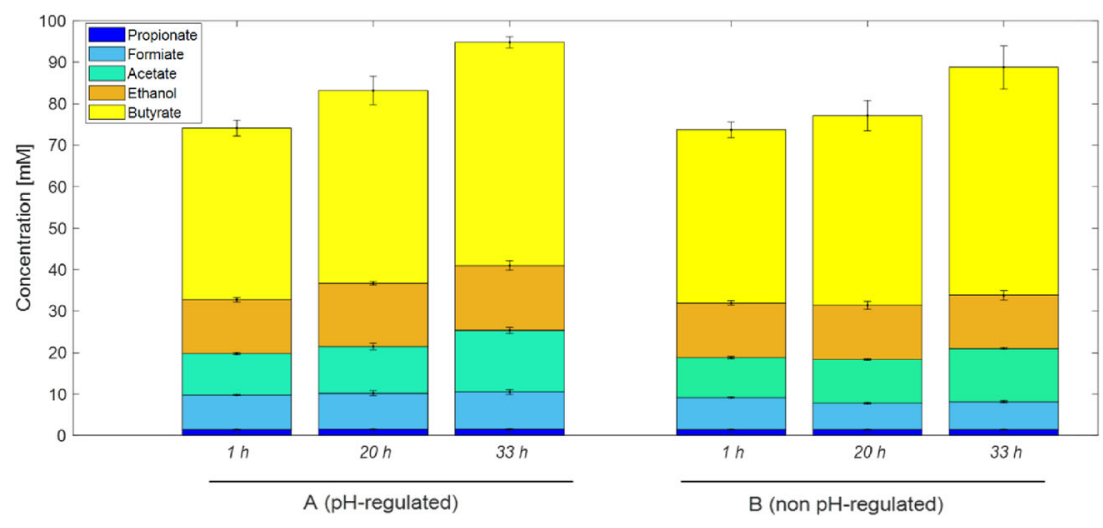

comparison between the negative control (not heattreated and unstained samples) and the positive control suggests that the SSC/BOX-A cytometric fingerprint could be used as an indicator of the PS of the mixed HPB fermentative microorganisms, since a clear shift in the relative fluorescence intensity in the channel for BOX detection (i.e., excitation at $488 \mathrm{~nm}$ and emission at $525 \mathrm{~nm}$ ) can be observed (Fig. 4e). Different staining protocols can be adopted for the evaluation of the PS through FC analysis of bacteria: either monocultures or mixed populations. A commonly measured parameter for the PS is the membrane potential. Cationic dyes accumulate in polarized cells, while anionic dyes (e.g., $\left.\mathrm{DiBaAC}_{4}(3)\right)$ accumulate in depolarized cells [53]. Additionally, the staining step included the addition of EDTA (see the "Flow Cytometry Analysis" section), which was aimed to increase the range of action of the dye and improve the reliability of the analysis for complex microbial communities (e.g., mixed bacteria, either Gram-positive or -negative) [54]. The calculations regarding the percentage of depolarized cells were performed using the triggering threshold shown in Fig. 4e, followed by the differentiation and comparison of the signal intensities of positive and negative (unstained cells) controls and the samples for each timepoint. Only a low amount of debris after the washing cycles with PBS $(<2 \%)$ was obtained and the instrument background was relatively low (data not shown). For the first timepoint measurement $(t=1 \mathrm{~h})$, systems (A) and (B) show no significant difference in the number of depolarized cells, which amounted to $23.06 \pm 4.60$ and $23.68 \pm 3.36 \%$, respectively. For the second point $(t=$ $20 \mathrm{~h}$ ), the system without $\mathrm{pH}$ control exhibits a share of depolarized cells, which is twice $(55.57 \pm 12.41 \%)$ the value of the one measured for the $\mathrm{pH}$-regulated system $(26.99 \pm 8.39 \%)$. Finally, at the end of the cultivation $(t=33 \mathrm{~h})$, the percentage of depolarized cells increased, reaching up to $30.31 \pm 1.34 \%$ for the $\mathrm{pH}$-regulated system, while the share for system (B) $(48.90 \pm 5.11 \%)$ slightly decreased compared with $t=20 \mathrm{~h}$. These differences among the $\mathrm{pH}$-regulated and non-regulated DF systems, in terms of relative levels of depolarized cells, as well as the different detected morphologies of the sporulation dynamics, seem similar with literature references [55].

\section{Frequency-Dependent Polarizability Anisotropy Measurements}

The results of the FDPA measurements, for both systems, are presented in Fig. 5. First of all, it must be noted that FDPA measurements are very sensitive to the presence of ions. Hence, an optimization of the sample preparation for accurate measurements was performed with varying dilution factors, biomass concentration, and centrifugation steps. Several tests were carried out (data not shown) to optimize the analytical

Table 3 Percentual time-resolved evolution of hypothesized FSC/SSC virtual clusters (sub-populations) from FC data

\begin{tabular}{|c|c|c|c|c|c|c|c|}
\hline \multirow[t]{2}{*}{ Virtual cluster } & \multicolumn{3}{|c|}{ pH-regulated system (A) } & \multicolumn{3}{|c|}{ Non pH-regulated system (B) } & \multirow[t]{2}{*}{ Associated morphology } \\
\hline & $t=1 \mathrm{~h}$ & $t=20 \mathrm{~h}^{*}$ & $t=33 \mathrm{~h}^{*}$ & $t=1 \mathrm{~h}$ & $t=20 \mathrm{~h}^{*}$ & $t=33 \mathrm{~h}^{*}$ & \\
\hline Group A & $31.72 \pm 0.02$ & $36.53 \pm 0.15$ & $55.51 \pm 0.34$ & $28.07 \pm 0.06$ & $34.14 \pm 0.11$ & $54.05 \pm 0.26$ & Free spore \\
\hline Group B & $50.78 \pm 0.14$ & $45.98 \pm 0.05$ & $32.11 \pm 0.21$ & $52.53 \pm 0.98$ & $44.79 \pm 0.50$ & $30.66 \pm 0.19$ & Rod-shaped \\
\hline Group C & $17.50 \pm 0.07$ & $17.49 \pm 0.07$ & $12.38 \pm 0.18$ & $19.40 \pm 0.11$ & $21.07 \pm 0.16$ & $15.29 \pm 0.31$ & Endospore \\
\hline
\end{tabular}

*The different time-evolution of the systems A and B for timepoints II and III is statistically significant at $p<0.05$. For additional information, see the Supplementary Material 


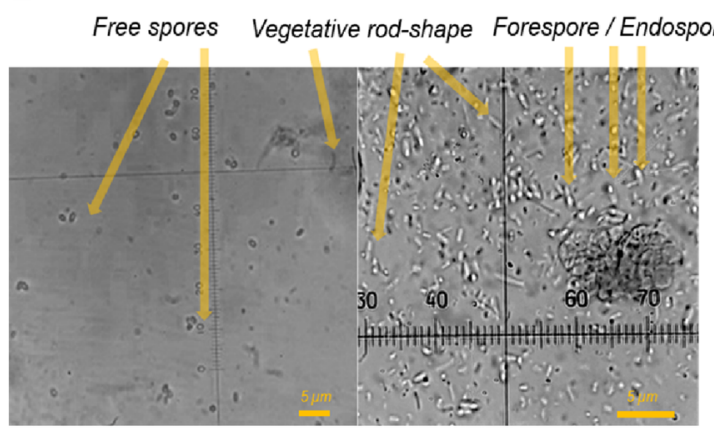

Acid-treated $A D$ sludge b

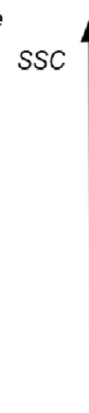

Pre-cultivated DF inoculum

d

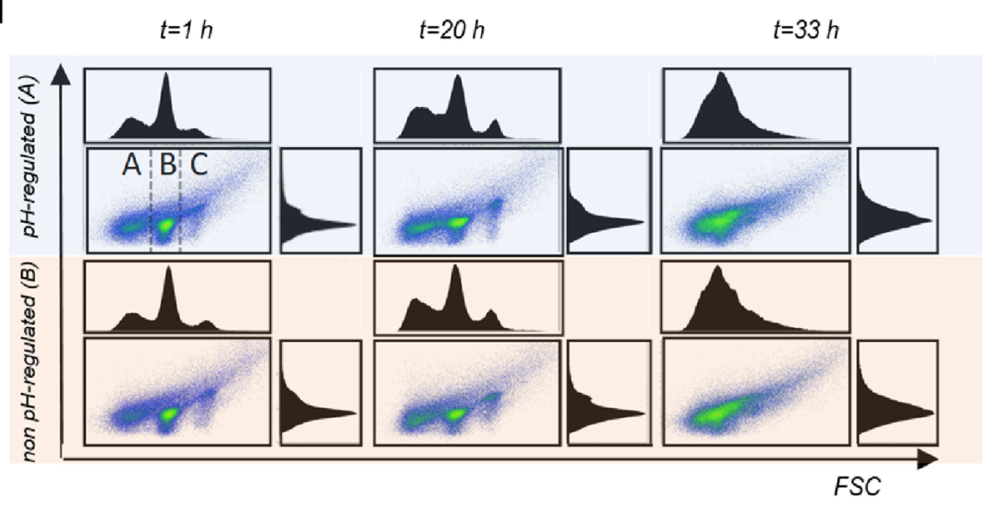

Fig. 4 Analysis of the DF culture: (a) microscopy of the acid-treated AD sludge and the pre-cultivated DF inoculum; (b) cytometric print (FSC/ SSC) during the pre-culture phase; (c) coupling virtual clusters (FC) and observed morphologies; (d) time evolution of the cytometric print (FSC/

$\mathrm{SSC}$ ) of the DF systems under pH-regulated and non-regulated conditions; (e) gating and triggering strategy (BOX-A/SSC) for the quantification of depolarized cells

protocol, and the final protocol is reported in the "FrequencyDependent Polarizability Anisotropy Measurements" section. In this respect, typical AD or DF broths exhibit high conductivity values (i.e., in the range $10-40 \mathrm{mS} / \mathrm{cm}$ ). The conductivity is a parameter that can be periodically measured to monitor process performance in $\mathrm{AD} \mathrm{[56].} \mathrm{However,} \mathrm{the} \mathrm{electrical} \mathrm{con-}$ ductivity of the fermentation broth, especially at high frequencies, could have an important effect on the FDPA measurements. Since FDPA measurements pertain to the biotic phase, the selection of ultra-deionized water for the suspension of microbial cells during the measurements resulted to be the best strategy.

Figure 5 shows that at the beginning of fermentation tests $(t=1 \mathrm{~h})$, the FDPA levels were high and similar for both systems under analysis, particularly at low frequencies. This fact probably suggests that the biotic phase presents a high activity due to the necessity to adapt to the new environment and that higher FDPA levels can be associated to the hydrolytic phase. Both systems (A and B), however, exhibited a decreasing trend of FDPA values along the course of fermentation due to substrate depletion and a concomitant decrease in hydrogen production. A possible explanation of these trends is that the systems reached a stable conformation in acidogenic conditions, where the PS (i.e., mean membrane cell polarizability in this case) is controlled by substrate availability, after the lag phase and hydrolysis. However, in the second measuring point $(t=20 \mathrm{~h})$, bioreactor (A) showed a higher FDPA level than system (B), most probably due to the controlled $\mathrm{pH}$ condition, which guarantees a constant environment for the mixed culture to grow and allow cells to maintain a constant membrane potential and well-functioning membrane transporter systems. These lower values of the FDPA level for the non-regulated $\mathrm{pH}$ system (B) are in accordance with the lower cumulative biohydrogen yields in Fig. 2b. For the last point $(t=33 \mathrm{~h})$, where the stationary phase was achieved, FDPA values are also similar for both systems (A and B), although for system (B), a slight increase compared with the $20 \mathrm{~h}$ sample was observed.

In general terms, bacteria cells are believed to exert control mechanisms to maintain constant values of the proton-motive force (pmf), balancing both components membrane potential $(\Delta \Psi)$ and homeostasis $(\Delta p H)$ [57], or to change the operative $p m f$ values due to metabolic shifts or to reduce $p m f$ thresholds when exposed to different stress conditions. For instance, $p m f$ values for Clostridium acetobutylicum have been estimated in the range of -99 and $-84 \mathrm{mV}$ when cultivated at $\mathrm{pH}$ conditions of 5.0 and 6.0, given by the $\Delta p H$ components of 59 and $28 \mathrm{mV}$ and the $\Delta \Psi$ component of -40 and $-56 \mathrm{mV}$, 

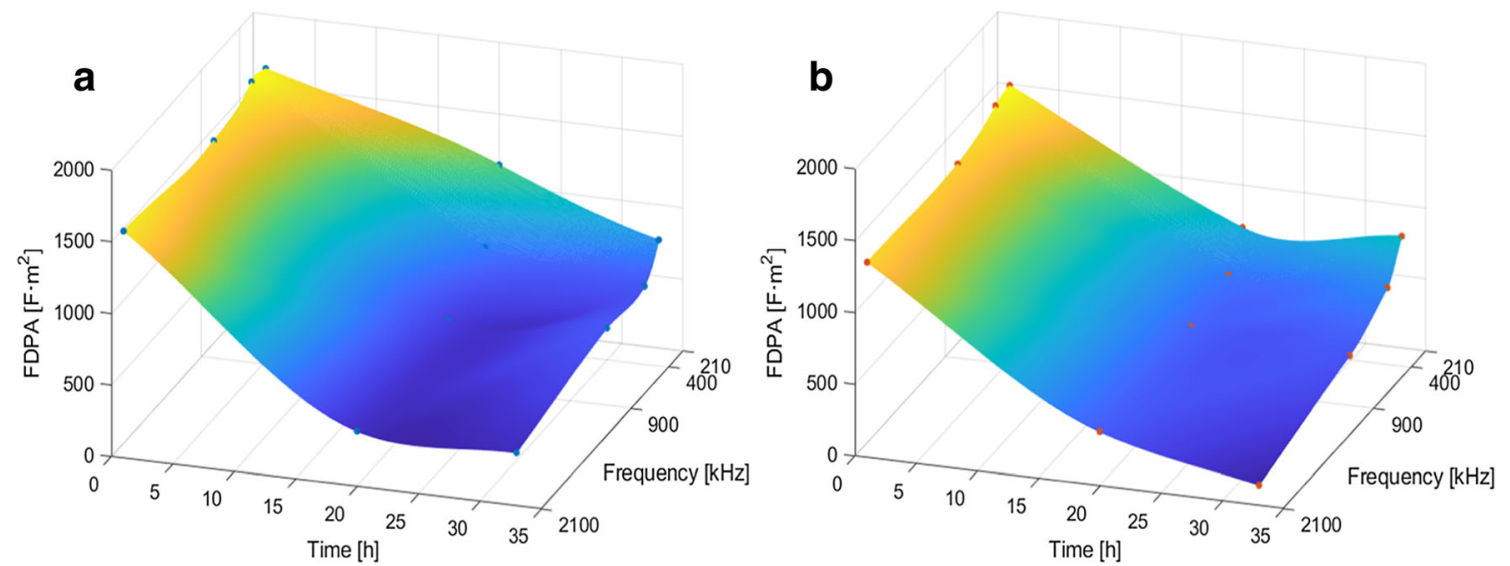

Fig. 5 Electrooptical measurements of FDPA at different frequencies, for the pH-regulated (a) and non-regulated (b) systems

respectively [58]. In the present case, the biotic phase was constituted by a mixture of acidogenic bacteria (based on the butyrate titers, presumably Clostridium spp. played the predominant role in the mixed consortium), and the $\mathrm{pH}$ stress was used as probe parameter. Although metabolic products (Fig. 3) did not significantly differ among the studied systems, the variations in the FDPA can be taken as a lumped indicator for the PS of the biotic phase based on the changes of the internal Maxwell-Wagner polarizability [59]. Additionally, it should be noted that the equilibrium of the organic acids of interest is shifted towards the non-dissociated form at low $\mathrm{pH}$ (i.e., under acidic conditions), which could additionally have stressed the non-regulated $\mathrm{pH}$ system (B). In this case, cells might spend a higher fraction of energy to counteract $\mathrm{pH}$ stress, in order to maintain homeostasis, rather than for growth, which can also partly explain the lower hydrogen yields in the gas output and reduced titers found in the liquid broth for system (B).

\section{Physiological State Correlation Between FDPA and FC}

Although there is no standard method for measuring the PS of mixed bacteria populations, the tested techniques, FC and FDPA measurements, proved to be helpful to track the PS dynamics of the open mixed culture used in the DF process. Both techniques are based on different physical measurement principles. On one hand, FDPA is a volumetric method that is based on the ionic properties of the cell suspension and its variations do reflect valuable information regarding the physiological state of the biotic phase. In the present case, different FDPA levels were useful to differentiate the phases of the culture (i.e., hydrolysis, acidogenesis, and starvation), as well as to compare the $\mathrm{pH}$-regulated with the non-regulated system. For monocultures, the cell size can also be determined using the relaxation times between the relaxed and excited states during FDPA measurements, which is an approach that might be extended for mixed cultures. On the other hand, the FC platform offers different levels of information regarding the microbial community structure. The FSC/SSC fingerprint can be useful to identify morphological changes and the relative abundance of key groups or sub-populations within microbial communities, while the selection of different fluorochromes can target, at monoculture and mixed culture level, different parameters to characterize the physiological state. The present results show an inverse correlation for both systems (A, B) between the obtained in the FDPA (Fig. 6a) and the percentage of depolarized cells calculated using FC (Fig. $6 \mathrm{~b}$ ). The FDPA values at $210 \mathrm{kHz}$ for system (A) showed an

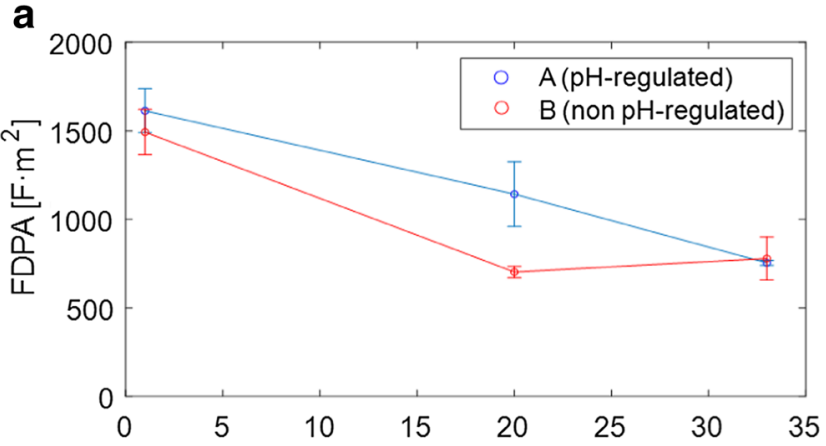

b

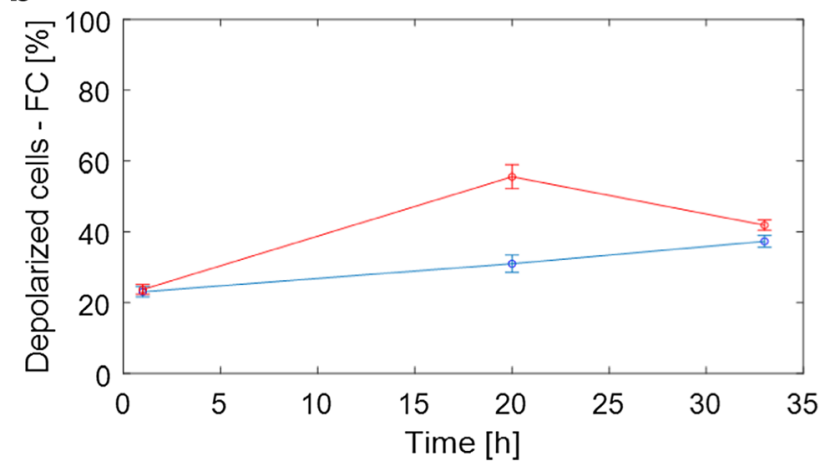

Fig. 6 Physiological state* estimation over the course of DF through FDPA measurements (a) and $\mathrm{DiBAC}_{4}(3)$-stained FC samples (b). *The different time-evolution of the systems A and B for $t=20 \mathrm{~h}$ is statistically significant at $p<0.05$. The FC measurements are also statistically significant at $p<0.05$ for $t=33 \mathrm{~h}$. For additional information, see the Supplementary Material 
almost linear decrease over time, while values of system (B) had a minimum at $20 \mathrm{~h}$. Importantly, FDPA measurements provide a mean value pertaining the whole cell population. Generally, microorganisms can either consume energy for dividing themselves (i.e., increase biomass) or to improve their intracellular status (i.e., increase polarizability, maintenance). At the beginning of the fermentation, the biotic phase is adapting to the actual environmental conditions and is therefore consuming energy basically for maintenance (i.e., high polarizability in both cases). As the cultivation evolves, there is a certain biomass growth over time and thus a steadily decline of the mean cell polarizability. Without $\mathrm{pH}$ control, microorganisms face the acidification stress, and therefore, they consume more energy for maintenance (i.e., higher polarizability, lower biomass, lower $\mathrm{H}_{2}$ production) when compared with system (A) at controlled $\mathrm{pH}$ at 6.0. These trends in FDPA measurements are consistent with the trends obtained by the FC measurements. For system (A), the percentage of depolarized cells increases continuously over time (although modestly), while for system (B), there is a maximum in the number of depolarized cells at time point $20 \mathrm{~h}$. Moreover, the cumulative-specific hydrogen evolution for each system (see Fig. 2) is also in agreement with the resulting trends of FDPA and FC measurements. At the timepoint $1 \mathrm{~h}$, the yield was similar for both systems, while the measurements at $20 \mathrm{~h}$ showed that system (B) only achieved a $77 \%$ of the yield of system (A) (i.e., the most critical condition as shown by FDPA and FC), and for the stationary phase, system (B) achieved $82 \%$ of the yield obtained in (A). Finally, it should be taken into consideration that the stress parameter for these tests was the influence of $\mathrm{pH}$ regulation, which might have impacted or stressed the biotic phase similarly, whether assessed by the FDPA or the FC technique. However, it is worth noting that for other stress conditions, the information independently provided by each technique can rather be supplementary.

\section{Conclusions}

The DF of complex feedstocks, such as agricultural products, is of great interest because it offers a great potential for process integration, with recovery of bioenergy in gaseous form (biohydrogen), and also as a liquid metabolite pool of chemicals of high valorization potential. The use of PATs can improve process performance by facilitating process integration and changing the paradigm regarding the physiology of open mixed cultures in DF and other black-box biotechnological processes. This approach can help to avoid process failures, such as substrate and/or product inhibitions, undesired population shifts, low metabolic activity, and suboptimal product yields. Here, the $\mathrm{pH}$ influence on the PS was useful to monitor the behavior of the DF systems in terms of biohydrogen and carboxylic acid productions as well as to assess physiological information in terms of morphology and key parameters related to the membrane polarizability by means of flow cytometry and electrooptical polarizability measurements. Although some industrial processes use sporulation-suppressed microbial strains, open mixed cultures for the production of biohydrogen and biochemicals might include sporulating strains, which can affect the process performance. Hence, morphological observations can be useful to determine groups and physiological states and to improve cellular performance. Additionally, the use of FC with $\operatorname{DiBAC}_{4}(3)$ staining and the measurements of the FDPA levels seem to be useful indicators for complex microbial cultures, and they can potentially facilitate monitoring of their PS during complex fermentations. A natural progression of this work is to analyze and assess the potential of these techniques to be used in continuous and large-scale processes and the development of control strategies for different biorefinery processes.

Funding Open access funding provided by Politecnico di Torino within the CRUI-CARE Agreement.

Open Access This article is licensed under a Creative Commons Attribution 4.0 International License, which permits use, sharing, adaptation, distribution and reproduction in any medium or format, as long as you give appropriate credit to the original author(s) and the source, provide a link to the Creative Commons licence, and indicate if changes were made. The images or other third party material in this article are included in the article's Creative Commons licence, unless indicated otherwise in a credit line to the material. If material is not included in the article's Creative Commons licence and your intended use is not permitted by statutory regulation or exceeds the permitted use, you will need to obtain permission directly from the copyright holder. To view a copy of this licence, visit http://creativecommons.org/licenses/by/4.0/.

\section{References}

1. NOVA Institut (2017) Biorefineries in Europe 2017. Hürth

2. Mona S, Kumar SS, Kumar V, Parveen K, Saini N, Deepak B, Pugazhendhi A (2020) Green technology for sustainable biohydrogen production (waste to energy): a review. Sci Total Environ 728:138481. https://doi.org/10.1016/j.scitotenv.2020. 138481

3. Gómez-Camacho CE, Ruggeri B (2018) Syntrophic microorganisms interactions in anaerobic digestion (AD): a critical review in the light of increase energy production. Chem Eng Trans 64:1-6. https://doi.org/10.3303/CET1864066

4. Castelló E, Nunes Ferraz-Junior AD, Andreani C, Anzola-Rojas MP, Borzacconi L, Buitrón G, Carrillo-Reyes J, Gomes SD, Maintinguer SI, Moreno-Andrade I, Palomo-Briones R, RazoFlores E, Schiappacasse-Dasati M, Tapia-Venegas E, ValdezVázquez I, Vesga-Baron A, Zaiat M, Etchebehere C (2020) Stability problems in the hydrogen production by dark fermentation: possible causes and solutions. Renew Sust Energ Rev 119: 109602. https://doi.org/10.1016/j.rser.2019.109602 
5. Pugazhendhi A, Kumar G, Sivagurunathan P (2019) Microbiome involved in anaerobic hydrogen producing granules: a mini review. Biotechnol Rep 21:e00301. https://doi.org/10.1016/j.btre.2018. e00301

6. Sivagurunathan P, Kuppam C, Mudhoo A, Saratale GD, Kadier A, Zhen G, Chatellard L, Trably E, Kumar G (2018) A comprehensive review on two-stage integrative schemes for the valorization of dark fermentative effluents. Crit Rev Biotechnol 38:868-882. https:// doi.org/10.1080/07388551.2017.1416578

7. Gómez-Camacho CE, Ruggeri B, Mangialardi L et al (2019) Continuous two-step anaerobic digestion (TSAD) of organic market waste: rationalising process parameters. Int J Energy Environ Eng 11:1-15. https://doi.org/10.1007/s40095-019-0312-1

8. Rasika K, Perera J, Ketheesan B et al (2010) Fermentative biohydrogen production: evaluation of net energy gain. Int $\mathrm{J}$ Hydrog Energy 35:12224-12233. https://doi.org/10.1016/j. ijhydene.2010.08.037

9. Gómez-Camacho CE, Ruggeri B (2019) Energy sustainability analysis (ESA) of energy-producing processes: a case study on distributed $\mathrm{H}_{2}$ production. Sustainability 11:4911. https://doi.org/10. 3390/su11184911

10. Wang A, Sun D, Cao G, Wang H, Ren N, Wu WM, Logan BE (2010) Integrated hydrogen production process from cellulose by combining dark fermentation, microbial fuel cells, and a microbial electrolysis cell. Bioresour Technol 102:4137-4143. https://doi. org/10.1016/j.biortech.2010.10.137

11. Mu D, Liu H, Lin W, Shukla P, Luo J (2020) Simultaneous biohydrogen production from dark fermentation of duckweed and waste utilization for microalgal lipid production. Bioresour Technol 302:122879. https://doi.org/10.1016/j.biortech.2020.122879

12. Bastidas-Oyanedel J-R, Bonk F, Thomsen MH, Schmidt JE (2019) The future perspectives of dark fermentation: moving from only biohydrogen to biochemicals. In: Biorefinery. Springer, Cham, pp 375-412

13. Show KY, Yan Y, Zong C, Guo N, Chang JS, Lee DJ (2019) State of the art and challenges of biohydrogen from microalgae. Bioresour Technol 289:121747. https://doi.org/10.1016/j.biortech. 2019.121747

14. Lu Y, Koo J (2019) $\mathrm{O}_{2}$ sensitivity and $\mathrm{H}_{2}$ production activity of hydrogenases - a review. Biotechnol Bioeng 116:3124-3135. https://doi.org/10.1002/bit.27136

15. Srivastava N, Srivastava M, Malhotra BD, Gupta VK, Ramteke PW, Silva RN, Shukla P, Dubey KK, Mishra PK (2019) Nanoengineered cellulosic biohydrogen production via dark fermentation: a novel approach. Biotechnol Adv 37:107384. https:// doi.org/10.1016/j.biotechadv.2019.04.006

16. Kumar G, Mathimani T, Sivaramakrishnan R, Shanmugam S, Bhatia SK, Pugazhendhi A (2020) Application of molecular techniques in biohydrogen production as a clean fuel. Sci Total Environ 722:137795. https://doi.org/10.1016/j.scitotenv.2020.137795

17. Odintsova V, Tyakht A, Alexeev D (2017) Guidelines to statistical analysis of microbial composition data inferred from metagenomic sequencing. Curr Issues Mol Biol 24:17-36. https://doi.org/10. 21775/cimb.024.017

18. Campanaro S, Treu L, Kougias PG, de Francisci D, Valle G, Angelidaki I (2016) Metagenomic analysis and functional characterization of the biogas microbiome using high throughput shotgun sequencing and a novel binning strategy. Biotechnol Biofuels 9:117. https://doi.org/10.1186/s13068-016-0441-1

19. Etchebehere C, Castelló E, Wenzel J, del Pilar Anzola-Rojas M, Borzacconi L, Buitrón G, Cabrol L, Carminato VM, Carrillo-Reyes J, Cisneros-Pérez C, Fuentes L, Moreno-Andrade I, Razo-Flores E, Filippi GR, Tapia-Venegas E, Toledo-Alarcón J, Zaiat M (2016) Microbial communities from 20 different hydrogen-producing reactors studied by 454 pyrosequencing. Appl Microbiol Biotechnol 100:3371-3384. https://doi.org/10.1007/s00253-016-7325-y
20. Campanaro S, Treu L, Rodriguez-R LM, Kovalovszki A, Ziels RM, Maus I, Zhu X, Kougias PG, Basile A, Luo G, Schlüter A, Konstantinidis KT, Angelidaki I (2020) New insights from the biogas microbiome by comprehensive genome-resolved metagenomics of nearly 1600 species originating from multiple anaerobic digesters. Biotechnol Biofuels 13:1-18. https://oi.org/ 10.1186/s13068-020-01679-y

21. Rathore AS, Chopda VR, Gomes J (2016) Knowledge management in a waste based biorefinery in the QbD paradigm. Bioresour Technol 215:63-75. https://doi.org/10.1016/j.biortech.2016.03.168

22. Cossar D (2019) Bioprocessing techniques. In: Moo-Young M (ed) Comprehensive biotechnology, 3rd edn. Elsevier, Waterloo, pp 688-701

23. Málek I, Fencl Z (1966) Theoretical and methodological basis of continuous culture of microorganisms. House of the Czechoslovak Academy of Sciences, Prague

24. Zentgraf B (1995) Physico-chemical methods for characterization of the physiological state of microorganisms. J Chem Technol Biotechnol 64:129-136. https://doi.org/10.1002/jctb.280640204

25. Lambrecht J, Cichocki N, Hübschmann T, Koch C, Harms H, Müller S (2017) Flow cytometric quantification, sorting and sequencing of methanogenic archaea based on F420 autofluorescence. Microb Cell Factories 16:1-15. https://doi.org/10.1186/ s12934-017-0793-7

26. Adan A, Alizada G, Kiraz Y, Baran Y, Nalbant A (2017) Flow cytometry: basic principles and applications. Crit Rev Biotechnol 37:163-176. https://doi.org/10.3109/07388551.2015.1128876

27. Lemoine A, Delvigne F, Bockisch A, Neubauer P, Junne S (2017) Tools for the determination of population heterogeneity caused by inhomogeneous cultivation conditions. J Biotechnol 251:84-93. https://doi.org/10.1016/j.jbiotec.2017.03.020

28. Lambrecht J, Schattenberg F, Harms H, Mueller S (2018) Characterizing microbiome dynamics - flow cytometry based workflows from pure cultures to natural communities. J Vis Exp. https://doi.org/10.3791/58033

29. Koch C, Fetzer I, Schmidt T, Harms H, Müller S (2013) Monitoring functions in managed microbial systems by cytometric bar coding. Environ Sci Technol 47:1753-1760. https://doi.org/10.1021/ es3041048

30. Branska B, Pechacova Z, Kolek J, Vasylkivska M, Patakova P (2018) Flow cytometry analysis of Clostridium beijerinckii NRRL B-598 populations exhibiting different phenotypes induced by changes in cultivation conditions. Biotechnol Biofuels 11:1-16. https://doi.org/10.1186/s13068-018-1096-x

31. Roy S, Vishnuvardhan M, Das D (2014) Continuous thermophilic biohydrogen production in packed bed reactor. Appl Energy 136: 51-58. https://doi.org/10.1016/j.apenergy.2014.08.031

32. Angersbach A, Bunin V, Ignatov O (2006) Electro-optical analysis of bacterial cells. In: Stoylov S, Stoimenova M (eds) Molecular and colloidal electro-optics, 1st edn. CRC Press, Boca Raton, pp $307-$ 326

33. Junne S, Nicolas Cruz-Bournazou M, Angersbach A, Götz P (2010) Electrooptical monitoring of cell polarizability and cell size in aerobic Escherichia coli batch cultivations. J Ind Microbiol Biotechnol 37:935-942. https://doi.org/10.1007/s10295-010-0742-5

34. Junne S, Klein E, Angersbach A, Goetz P (2008) Electrooptical measurements for monitoring metabolite fluxes in acetone-butanol-ethanol fermentations. Biotechnol Bioeng 99:862-869. https://doi.org/10.1002/bit.21639

35. Pellicer-Alborch K, Angersbach A, Neubauer P, Junne S (2018) Electrooptical determination of polarizability for on-line viability and vitality quantification of Lactobacillus plantarum cultures. Front Bioeng Biotechnol 6:1-10. https://doi.org/10.3389/fbioe. 2018.00188 
36. Habermann B, Ritzi E, Schulze F (2015) Monitoring of biogas plants - experiences in laboratory and full scale. Carbon-Sci Technol 7:1-7

37. Ruggeri B, Tommasi T, Sanfilippo S (2015) $\mathrm{BioH}_{2}$ \& $\mathrm{BioCH}_{4}$ through anaerobic digestion: from research to full-scale applications. Springer, London

38. Pineda-Muñoz CF, Conde-Baez L, Lucho-Constantino C, MedinaMoreno SA, Jiménez-González A (2020) Ultrasonic energy effect on dark fermentation by ultrasound application alone and in combination with heat shock. BioEnergy Res 13:334-338. https://doi. org/10.1007/s12155-020-10104-Z

39. Lemoine A, Maya Martnez-Iturralde N, Spann R et al (2015) Response of Corynebacterium glutamicum exposed to oscillating cultivation conditions in a two- and a novel three-compartment scale-down bioreactor. Biotechnol Bioeng 112:1220-1231. https://doi.org/10.1002/bit.25543

40. Cieciura-Włoch W, Borowski S, Otlewska A (2020) Biohydrogen production from fruit and vegetable waste, sugar beet pulp and corn silage via dark fermentation. Renew Energy 153:1226-1237. https://doi.org/10.1016/j.renene.2020.02.085

41. Shupek E, Makoś P, Kucharska K, Gęicki J (2020) Mesophilic and thermophilic dark fermentation course analysis using sensor matrices and chromatographic techniques. Chem Pap 74:1573-1582. https://doi.org/10.1007/s11696-019-01010-6

42. Ilgi K, Onur B (2020) Biohydrogen production from acid hydrolyzed wastewater treatment sludge by dark fermentation. Int $\mathrm{J}$ Hydrog Energy 45:3499-3508. https://doi.org/10.1016/j.ijhydene. 2019.03.230

43. Penniston J, Gueguim Kana EB (2018) Impact of medium pH regulation on biohydrogen production in dark fermentation process using suspended and immobilized microbial cells. Biotechnol Biotechnol Equip 32:204-212. https://doi.org/10.1080/13102818. 2017.1408430

44. Deng C, Lin R, Cheng J, Murphy JD (2019) Can acid pre-treatment enhance biohydrogen and biomethane production from grass silage in single-stage and two-stage fermentation processes? Energy Convers Manag 195:738-747. https://doi.org/10.1016/j. enconman.2019.05.044

45. Pakarinen O, Lehtoma A, Rintala J (2008) Batch dark fermentative hydrogen production from grass silage: the effect of inoculum, $\mathrm{pH}$, temperature and VS ratio. Int J Hydrog Energy 33:594-601. https:// doi.org/10.1016/j.ijhydene.2007.10.008

46. Pakarinen O, Tahti H, Rintala $\mathrm{J}$ (2009) One-stage $\mathrm{H}_{2}$ and $\mathrm{CH}_{4}$ and two-stage $\mathrm{H}_{2}+\mathrm{CH}_{4}$ production from grass silage and from solid and liquid fractions of $\mathrm{NaOH}$ pre-treated grass silage. Biomass Bioenergy 33:1419-1427. https://doi.org/10.1016/j.biombioe. 2009.06.006

47. Martin PCB, Schlienz M, Greger M (2017) Production of biohydrogen and methane during semi-continuous digestion of maize silage in a two-stage system. Int J Hydrog Energy 42:5768-5779. https://doi.org/10.1016/j.ijhydene.2017.01.020
48. Nkongndem V, Gilroyed B, Yanke J et al (2015) Bioresource technology bioaugmentation with an anaerobic fungus in a two-stage process for biohydrogen and biogas production using corn silage and cattail. Bioresour Technol 185:79-88. https://doi.org/10.1016/ j.biortech.2015.02.100

49. Ma S, Wang H, Wang Y, Bu H, Bai J (2011) Bio-hydrogen production from cornstalk wastes by orthogonal design method. Renew Energy 36:709-713. https://doi.org/10.1016/j.renene.2010. 08.019

50. Bundhoo MAZ, Mohee R (2016) Inhibition of dark fermentative bio-hydrogen production: a review. Int J Hydrog Energy 41:67136733. https://doi.org/10.1016/J.IJHYDENE.2016.03.057

51. Khanal SK, Chen WH, Li L, Sung S (2004) Biological hydrogen production: effects of $\mathrm{pH}$ and intermediate products. Int $\mathrm{J}$ Hydrog Energy 29:1123-1131. https://doi.org/10.1016/j.ijhydene.2003.11. 002

52. Patakova P, Branska B, Sedlar K, Vasylkivska M, Jureckova K, Kolek J, Koscova P, Provaznik I (2019) Acidogenesis, solventogenesis, metabolic stress response and life cycle changes in Clostridium beijerinckii NRRL B-598 at the transcriptomic level. Sci Rep 9:1-21. https://doi.org/10.1038/s41598-018-37679-0

53. Silva TL, Roseiro JC, Reis A (2012) Applications and perspectives of multi-parameter flow cytometry to microbial biofuels production processes. Trends Biotechnol 30:225-231. https://doi.org/10.1016/ j.tibtech.2011.11.0053

54. Sträuber H, Müller S (2010) Viability states of bacteria-specific mechanisms of selected probes. Cytom Part A 77A:623-634. https://doi.org/10.1002/cyto.a.20920

55. Kolek J, Branska B, Drahokoupil M, Patakova P, Melzoch K (2016) Evaluation of viability, metabolic activity and spore quantity in clostridial cultures during ABE fermentation. FEMS Microbiol Lett 363:1-8. https://doi.org/10.1093/femsle/fnw031

56. Robles A, Latrille E, Ribes J, Bernet N, Steyer JP (2016) Electrical conductivity as a state indicator for the start-up period of anaerobic fixed-bed reactors. Water Sci Technol 73:2294-2300. https://doi. org/10.2166/wst.2016.031

57. Farha MA, Verschoor CP, Bowdish D, Brown ED (2013) Collapsing the proton motive force to identify synergistic combinations against Staphylococcus aureus. Chem Biol 20:1168-1178. https://doi.org/10.1016/j.chembiol.2013.07.006

58. Huang L, Gibbins LN, Forsberg CW (1985) Transmembrane pH gradient and membrane potential in Clostridium acetobutylicum during growth under acetogenic and solventogenic conditions. Appl Environ Microbiol 50:1043-1047

59. Zhivkov AM, Gyurova AY (2009) Influence of cytoplasm electrolyte concentration on Maxwell-Wagner polarizability of bacteria E. coli. J Phys Chem B 113:8375-8382. https://doi.org/10.1021/ jp810020p

Publisher's Note Springer Nature remains neutral with regard to jurisdictional claims in published maps and institutional affiliations. 